\title{
Predictive testing for two neurodegenerative disorders (FAP and HD): A psychological point of view
}

\author{
Lêdo Susana $^{1,2,3}$, Paneque Milena ${ }^{1,2}$, Rocha José ${ }^{3}$, Leite Ângela ${ }^{1,4,5}$, Sequeiros Jorge ${ }^{1,2}$ \\ ${ }^{1}$ Centre for Predictive and Preventive Genetics (CGPP), Institute for Molecular and Cell Biology (IBMC), Porto, Portugal \\ ${ }^{2}$ ICBAS, Universidade do Porto, Porto, Portugal \\ ${ }^{3}$ UnIPSa, Centro de Investigação em Ciências da Saúde (CICS), Instituto Superior de Ciências da Saúde, CESPU, Paredes, Portugal \\ ${ }^{4}$ Instituto Superior de Ciências Empresariais e do Turismo (ISCET), Porto, Portugal \\ ${ }^{5}$ Universidade Lusófona do Porto (ULP), Porto, Portugal \\ Email: susanaledo@gmail.com
}

Received 21 October 2013; revised 18 November 2013; accepted 5 December 2013

Copyright (C) 2013 Lêdo Susana et al. This is an open access article distributed under the Creative Commons Attribution License, which permits unrestricted use, distribution, and reproduction in any medium, provided the original work is properly cited.

\begin{abstract}
In this retrospective study, we have researched the psychological impact of pre-symptomatic testing (PST) for 2 autosomal dominant late-onset diseases: Huntington disease (HD and familial amyloidotic polyneuropathy (FAP) V30M TTR. The study included 53 subjects: $40(75.5 \%)$ were the offspring at risk for FAP and $13(24.5 \%)$ for HD. Of these, $38(73.1 \%)$ received the carrier result and $12(23.1 \%)$ the noncarrier result; 3 of them did not want to know the result. The indicators taken for emotional distress were the subscales and global indexes of psychopathological Behavior Symptoms Inventory (BSI), applied in the pre-test and post-test, one-year after notification of results. Values decreased significantly one year after the implementation of the PST, regardless of the studied disease or test result; this seems to corroborate previous studies showing that testing does not increase pre-symptomatic levels of emotional disturbance in individuals. However, the subjects studied showed, for all subscales and global indexes of the BSI, significantly higher values than those of control groups.
\end{abstract}

Keywords: Psychopathologic Indexes; Subscales; BSI; Psychological Impact; FAP; HD

\section{INTRODUCTION}

Huntington's disease (HD) and Amyloidotic Polyneuropathy (FAP) TTR V30M are late onset autosomal dominant diseases for which pre-symptomatic testing (PST) is available [1-3]. PST can predict if, in a more or less distant future, subjects identified as at risk will develop symptoms of the disease $[2,4]$.
Since 1992, the Center for Predictive and Preventive Genetics (CGPP) provides a multidisciplinary approach for the PST of HD and PAF and has become a national reference institution in genetic counseling and psychosocial support for people who are at risk of such progressive and debilitating diseases which are still without effective treatment and cure [2].

\section{The Diseases}

HD and FAP are two examples of late-onset neurodegenerative disorders (LONDs), incurable and highly debilitating.

Huntington's disease $[5,6]$ is the most studied, largely due to the Gusella and colleagues discovery of its genetic marker in 1983 [7]. The predictive test for Huntington's disease began to be applied in Canada in 1986 and in the US [1,8], and the 90's was a decade of scientific progress, namely new laboratory techniques for mutation detection [5-7].

FAP $[9,10,12]$ is a very specific Portuguese disease, that also has severe neurodegenerative pathways and for which there is still no effective treatment or cure.

Several psychosocial studies have been done in families and their descendants at risk for neurodegenerative diseases are diagnosed in CGPP [12-15].

Lêdo [12] studied FAP carriers, concluding that after a year of knowledge of their genetic status, there was absence of emotional distress and feelings of hopelessness.

Other studies concerning subjects at risk for FAP and HD pointed to the existence of psychological well-being and better health perception than control subjects [13]. Also in this field, psychosocial genetic studies have been published focusing on a lengthier experience of more than 10 years after counseling of individuals at risk [14], as well as research on the topic of the effects of contact time with the 
disease or the parent affected in the psychological outcome of PST [15].

Despite the different approaches, there are still issues regarding the impact of the application of PST to diseases with similar first symptoms at the early adulthood and a degenerative path, but with different treatment options and clinical outcomes (e.g. the psychiatric disorders, unique to Huntington's disease). It continues to be relevant to research to correlate the psychological impact of the test results with other variables such as cultural and socio-demographic profile of this population. Hence, the following was established as objectives of this research: 1) to compare the BSI psychopathological indices observed before and one year after completion of the PST and 2) to differentiate psychological impact related to a type of risk disease, carrier or non-carrier status and demographic variables (age, gender, marital status) included in the general protocol.

\section{MATERIAL AND METHODS}

A retrospective study of clinical files was designed based on subjects who underwent pre-symptomatic testing for genetic autosomal dominant diseases with late onset (HD and FAP), in CGPP, between 2000 and 2010. These files contained data regarding the psychological evaluations conducted along the four moments of the general psychological evaluation protocol: 1) 1st moment, pre-test, prior to the genetic test; 2) 2nd moment, three weeks after receiving the test result and knowing the genetic status; 3) 3rd moment, six months after disclosure; 4) 4th moment, one year after disclosure.

In the present study only two specific moments were considered, corresponding to the psychopathological inventory here applied: pre-test, 1 st moment a, and one year after disclosure (post-test or 4th moment d).

\subsection{Subjects}

The initial sample (Table 1) comprised 686 subjects at baseline: $586(85.4 \%)$ came in to undertake the presymptomatic test for FAP, $92(13.4 \%)$ for HD and 8 (1.2\%) for MJD (Machado Joseph Disease). 58.6\% of the subjects were female. It was found that $51.3 \%$ of the participants were single, $44.7 \%$ were married. From the initial total, 29 did not appear to receive the test result, $352(51.6 \%)$ were given a positive result as carriers and $305(44.7 \%)$ received the result of non-carriers for the tested condition. At any of the given four moments of the general protocol some participants abandoned the intended follow-ups. The presumed causes for this outcome are either being given the result of non-carriers, hence no recognition of need to stay in the study or being given the result of carrier, unwillingness to follow protocol. This is why there was a sharp decline in the subject number at the post-test one year later.

Men and women have proven to be equivalent in their distribution regarding the criteria age $\left(\mathrm{X}^{2}=\right.$ 636.939 , df $=625, \mathrm{p}=0.362)$, marital status $\left(\mathrm{X}^{2}=\right.$ $5.733, \mathrm{df}=2, \mathrm{p}=0.057)$, and the outcome of test result $\left(\mathrm{X}^{2}=2.446, \mathrm{df}=2, \mathrm{p}=0.294\right)$.

However, we found that from initial 686 subjects, only 53 attended the 4 th moment. Thus, we decided to compare only the BSI values of these 53 subjects who were present in the 1 st and 4th moment of evaluation and considered solely FAP and HD subjects since there were just one subject at 4th moment for MJD (Table 2).

Then the sample comprises 53 subjects with an average age of 35.19 years $(\mathrm{SD}=10.11$ years, between 21 and 60 years) (Table 2): 40 (75.5\%) came in to undertake the pre-symptomatic test for FAP and $13(24.5 \%)$ for HD. $60.4 \%$ (32) of the subjects were female. It was found that $46.2 \%$ (24) of the participants were single,

Table 1. Sample Characteristics along the four moments of the general psychological evaluation protocol.

\begin{tabular}{|c|c|c|c|c|c|c|c|c|c|c|c|c|}
\hline & \multicolumn{3}{|c|}{ Pre Test a $(N=686)$} & \multicolumn{3}{|c|}{ Post Test b $(N=290)$} & \multicolumn{3}{|c|}{ Post Test c $(N=143)$} & \multicolumn{3}{|c|}{ Post Test d $(N=54)$} \\
\hline & FAP & HD & MJD & FAP & HD & MJD & FAP & HD & MJD & FAP & HD & MJD \\
\hline$N$ & 586 & 92 & 8 & 248 & 38 & 4 & 114 & 25 & 4 & 40 & 13 & 1 \\
\hline Gender & $\begin{array}{c}\text { F } 340 \\
\text { M } 246\end{array}$ & $\begin{array}{l}\text { F } 54 \\
\text { M } 38\end{array}$ & $\begin{array}{l}\text { F } 8 \\
\text { M } 0\end{array}$ & $\begin{array}{l}\text { F } 146 \\
\text { M } 102\end{array}$ & $\begin{array}{c}\text { F } 20 \\
\text { M } 18\end{array}$ & $\begin{array}{l}\text { F } 4 \\
\text { M } 0\end{array}$ & $\begin{array}{c}\text { F } 64 \\
\text { M } 50\end{array}$ & $\begin{array}{l}\text { F } 14 \\
\text { M } 11\end{array}$ & $\begin{array}{l}\text { F } 4 \\
\text { M } 0\end{array}$ & $\begin{array}{l}\text { F } 25 \\
\text { M } 15\end{array}$ & $\begin{array}{l}\text { F } 7 \\
\text { M } 6\end{array}$ & $\begin{array}{l}\text { F } 1 \\
\text { M } 0\end{array}$ \\
\hline Mean Age & 35.09 & 43.69 & 38.75 & 34.83 & 46.45 & 48.00 & 34.68 & 45.24 & 48.00 & 31.85 & 45.46 & 37.00 \\
\hline $\begin{array}{c}\text { Marital } \\
\text { Status }\end{array}$ & $\begin{array}{c}\text { S } 320 \\
\text { M } 239 \\
\text { D } 10 \\
\text { W } 8\end{array}$ & $\begin{array}{c}\text { S } 27 \\
\text { M } 59 \\
\text { D } 0 \\
\text { W } 0\end{array}$ & $\begin{array}{c}\text { S } 2 \\
\text { M } 6 \\
\text { D } 0 \\
\text { W } 0\end{array}$ & $\begin{array}{c}\text { S } 134 \\
\text { M } 104 \\
\text { D } 3 \\
\text { W } 3\end{array}$ & $\begin{array}{c}\text { S } 13 \\
\text { M } 23 \\
\text { D } 1 \\
\text { W } 1\end{array}$ & $\begin{array}{c}\text { S } 1 \\
\text { M } 3 \\
\text { D } 0 \\
\text { W } 0\end{array}$ & $\begin{array}{c}\text { S } 59 \\
\text { M } 52 \\
\text { D 0 } \\
\text { W 1 }\end{array}$ & $\begin{array}{c}\text { S } 9 \\
\text { M } 14 \\
\text { D } 1 \\
\text { W } 1\end{array}$ & $\begin{array}{c}\text { S } 1 \\
\text { M } 3 \\
\text { D } 0 \\
\text { W } 0\end{array}$ & $\begin{array}{c}\text { S } 22 \\
\text { M } 17 \\
\text { D } 0 \\
\text { W } 0\end{array}$ & $\begin{array}{c}\text { S } 2 \\
\text { M } 11 \\
\text { D } 0 \\
\text { W } 0\end{array}$ & $\begin{array}{l}\text { S } 0 \\
\text { M } 1 \\
\text { D } 0 \\
\text { W } 0\end{array}$ \\
\hline $\begin{array}{c}\text { Test } \\
\text { Result }\end{array}$ & $\begin{array}{c}\text { NC } 311 \\
\text { C } 254 \\
\text { DK } 17\end{array}$ & $\begin{array}{c}\text { NC } 39 \\
\text { C } 45 \\
\text { DK } 8\end{array}$ & $\begin{array}{c}\text { NC } 2 \\
\text { C } 6 \\
\text { DK } 0\end{array}$ & $\begin{array}{c}\mathrm{NC} 124 \\
\mathrm{C} 117 \\
\mathrm{DK} 5\end{array}$ & $\begin{array}{c}\mathrm{NC} 16 \\
\mathrm{C} 21 \\
\mathrm{DK} 1\end{array}$ & $\begin{array}{c}\text { NC } 0 \\
\text { C } 4 \\
\text { DK } 0\end{array}$ & $\begin{array}{c}\mathrm{NC} 47 \\
\mathrm{C} 62 \\
\mathrm{DK} 3\end{array}$ & $\begin{array}{l}\text { NC } 5 \\
\text { C19 } \\
\text { DK } 1\end{array}$ & $\begin{array}{c}\mathrm{NC} 0 \\
\mathrm{C} 4 \\
\mathrm{DK} 0\end{array}$ & $\begin{array}{c}\text { NC } 10 \\
\text { C } 29 \\
\text { DK } 0\end{array}$ & $\begin{array}{c}\mathrm{NC} 2 \\
\mathrm{C} 9 \\
\mathrm{DK} 2\end{array}$ & $\begin{array}{c}\mathrm{NC} 0 \\
\mathrm{C} 1 \\
\mathrm{DK} 0\end{array}$ \\
\hline
\end{tabular}

Gender (Female; Male); Marital Status (Single; Married; Divorced; Widow); Test Result (Non-Carrier; Carrier; Don't know). 
Table 2. Sample characteristics of the 53 subjects that finished the general psychological evaluation protocol.

\begin{tabular}{ccc}
\hline & \multicolumn{2}{c}{ Total Pre-Test } \\
\hline $\mathbf{N}$ & 53 & $100 \%$ \\
Gender & $\mathrm{F}-32$ & $\mathrm{~F}-60.4 \%$ \\
& $\mathrm{M}-21$ & $\mathrm{M}-39.6 \%$ \\
Age & 35.19 & 10.1 \\
& & $\mathrm{~S}-46.2 \%$ \\
Marital Status & $\mathrm{S}-24$ & $\mathrm{M}-53.8 \%$ \\
\hline
\end{tabular}

Gender (Female; Male); Marital Status (Single; Married; Divorced; Widow); Test Result (Non-Carrier; Carrier; Don't know).

$53.8 \%$ (28) were married. $38(73.1 \%)$ were given a positive result as carriers and $12(23.1 \%)$ received the result of non-carriers for the tested condition; $3(5.7 \%)$ subjects decided not to know their genetic result (this result cannot be known by us, until the subject know it).

\subsection{Procedure}

The PST protocol queries for neurodegenerative diseases in CGPP have been published elsewhere [2].

In the context of the protocol, each subject answered the BSI inventory at two stages: 1) pre-test, the first psychological evaluation - comprises a survey and evaluation of the motivations that led the person to presymptomatic testing, exploring his/her own decision making processes and detection of emotional distress that might jeopardize a good adjustment to the predictive test result, 2) post-test, one year after reporting the genetic test result.

The socio-demographic variables (gender, age and marital status) and medical history were collected at the first psychological evaluation.

The psychological variables were collected by applying the Brief Symptom Inventory-BSI [16]—adapted for the Portuguese population by Canavarro $[17,18]$.

The above mentioned inventory has 53 items rated on a Likert scale of five grades (0 "rarely" to 4 "very often"). It evaluates the psychopathological symptoms considering nine dimensions and three global indices [16], which translate psychometric ratings of emotional distress and its dimensions are: somatization (items 2, 7, 23, 29, 30, 33, 37), obsessive-compulsive (items 5, 15, $26,27,32,36$ ), interpersonal sensitivity (items 20, 21, 22,42 ), depression (items 9, 16, 17, 18, 35, 50), anxiety (items 1, 12, 19, 38, 45, 49), hostility (items 6, 13, 40, $31,46)$, phobic anxiety (items $8,28,31,43,47)$, paranoid ideation (items $4,10,24,48,51$ ), and psychosis (or psychoticism) (items 3, 14, 34, 44, and 53).

In addition to the subscales, this inventory includes three indices that capture global psychological distress: 1) global severity index (GSI), which is the average of all subscale scores (e.g., 53, if there are no answers blank), 2) positive symptoms total (PST), which is the number of items endorsed at a level higher than zero, 3) positive symptom distress index (PSD), which corresponds to the sum of all item values divided by the PST. A PSD index $\geq 1.7$ reflects the possible presence of emotional disturbance and "a lower value is present in the general population" [18].

\subsection{Data Analysis}

Statistical analysis was performed using the Statistical Program for Social Sciences (SPSS), version 18.0 for Windows.

The differences between groups, regarding the psychological measurements, were tested with the Student's $t$ test and ANOVA; we also use regression analysis in order to make predictions of some variables.

\section{RESULTS}

\subsection{Pre-Test}

At this stage, the average values of the BSI subscales, as well as the average indices of the inventory, basically revealed the absence of emotional pathology. If the values presented by Canavarro [17] for the general population are taken as reference, the values of the BSI, at the pre-test stage, are higher. However, they are still lower than the portuguese population considered to be suffering from emotional disturbance [17], as can be seen in Table 3.

When compared the BSI variables with some sociodemographic variable, no significantly different values in all subscales were found at the pre-test stage for the gender and age variables.

A socio-demographic variable that showed some statistically significant results was marital status. The somatization subscale revealed statistically significant different values in relation to marital status: single had lower average scores of somatization than married (Table 4).

Another socio-demographic variable that showed statistically significant results was type of disease. The somatization subscale revealed statistically significant different values in relation to type of disease: subjects at risk for FAP had lower average scores of somatization than subjects at risk for HD (Table 5).

\subsection{Post-Test}

Regarding the post-test BSI (BSId) implementation, the average scores obtained on the subscales and indixes decreased when compared to pre-test BSI (BSIa) (Table 6).

With respect to the subjects at risk for FAP, the values 
Table 3. Comparison of the average values for the subscales and indices of the BSI at pre-test with normalization references for the Portuguese general population and disturbed population (Canavarro, 1999).

\begin{tabular}{|c|c|c|c|c|c|c|c|}
\hline \multicolumn{4}{|c|}{ Averages and indexes of the subscales at pre-test } & \multicolumn{2}{|c|}{$\begin{array}{l}\text { General Population } \\
\text { Canavarro (1999) }\end{array}$} & \multicolumn{2}{|c|}{$\begin{array}{c}\text { Emotional Disturbed Population } \\
\text { Canavarro (1999) }\end{array}$} \\
\hline Subscales & $N$ & Mean & $S D$ & Mean & $S D$ & Mean & $S D$ \\
\hline Somatization & 53 & 4.226 & 4.734 & 0.573 & 0.916 & 9.445 & 7.032 \\
\hline Obs. compulsive & 53 & 5.906 & 4.143 & 1.290 & 0.878 & 11.534 & 5.567 \\
\hline Interp. sensitivity & 53 & 3.094 & 2.870 & 0.958 & 0.727 & 6.404 & 4.143 \\
\hline Depression & 53 & 4.094 & 4.221 & 0.893 & 0.722 & 11.034 & 6.275 \\
\hline Anxiety & 53 & 4.415 & 3.734 & 0.942 & 0.766 & 10.521 & 5.658 \\
\hline Hostility & 53 & 3.877 & 3.238 & 0.894 & 0.784 & 7.034 & 4.529 \\
\hline Phobic anxiety & 53 & 2.038 & 2.572 & 0.418 & 0.663 & 5.082 & 4.656 \\
\hline Paranoid ideat & 53 & 4.472 & 3.195 & 1.063 & 0.789 & 7.651 & 4.263 \\
\hline Psychosis & 53 & 2.717 & 3.066 & 0.668 & 0.614 & 7.021 & 4.140 \\
\hline Indexes & $N$ & Mean & $S D$ & & & & \\
\hline GSI & 53 & 0.703 & 0.526 & 0.835 & 0.480 & 1.430 & 0.705 \\
\hline PST & 53 & 23.132 & 12.862 & 26.993 & 11.724 & 37.349 & 12.166 \\
\hline PSD & 53 & 1.506 & 0.382 & 1.561 & 0.385 & 2.111 & 0.595 \\
\hline
\end{tabular}

Table 4. Comparison between average values of the subscales and indexes of the BSI in relation to the variable marital status at pre-test.

\begin{tabular}{cccccc}
\hline \multicolumn{2}{c}{ Subscales BSIa } & Mean & $\boldsymbol{N}$ & $\boldsymbol{F}$ & Sig. \\
\hline \multirow{2}{*}{ Somatization } & Single & 2.750 & 24 & & \\
& Married & 5.321 & 29 & & \\
\hline
\end{tabular}

Table 5. Comparison between average values of the subscales and indexes of the BSI in relation to the type of disease at pretest.

\begin{tabular}{lccccc}
\hline \multicolumn{2}{c}{ Subscales BSIa } & Mean & $\boldsymbol{N}$ & $\boldsymbol{F}$ & Sig. \\
\hline \multirow{2}{*}{ Somatization } & FAP & 3.450 & 40 & & \\
& HD & 6.615 & 13 & & \\
\hline
\end{tabular}

of the BSI subscales and indexes are also lower at posttest moment than at the pre-test. The same applies to subjects at risk for HD. When comparing samples for FAP and HD, we found that in the pre-test subjects at risk for HD present higher values for all BSI subscales and indexes, except for phobic anxiety and paranoid ideation subscales.

The subjects who transitioned from pre-test moment to post-test are mainly carriers (Table 7).

When comparing carriers and non carriers samples, at post-test, we found that carriers present higher values for all BSI subscales and indexes, except for hostility, para- noid ideation and psychosis subscale and PSD.

When comparing samples of FAP and HD carriers, at post-test, we found that HD carriers present higher values for all BSI subscales and indexes, except paranoid ideation subscale and PSD.

If we compare samples of FAP and HD non carriers, at post-test, we found that FAP non carriers present higher values for all BSI subscales and indexes; this can be explained by the low number of HD non carriers that remained in the protocol.

However, the differences between the averages of the subscales and indexes regarding the sociodemographic variables (gender, age, marital status) and type of disease and test result variables are not statistically significant.

\subsection{Comparison between the BSI Subscales in the Two Moments}

It was found that the average values for all subscales of the BSI declined significantly after the year in which the outcome of PST was made $(\mathrm{p}<0.05)$ (Table 8).

There was also a decrease in the average values obtained for the scores of GSI $(\mathrm{t}=3.837$; $\mathrm{df}=53 ; \mathrm{p}=$ $0.00)$ and PST $(\mathrm{t}=4.140, \mathrm{df}=53, \mathrm{p}=0.00)$.

From the PSD it was possible to know the degree of pathology, with reference to the score 1.7 as the cut point from which emotional disturbance is revealed [17] (Canavarro et al., 1999) (Table 8). In no time, the PSD value equaled or exceeded the cut point. 
Table 6. Average scores for the pre and post-test BSI subscales and indexes.

\begin{tabular}{|c|c|c|c|c|c|c|c|c|c|c|c|c|}
\hline \multirow[b]{3}{*}{$\mathbf{N}$} & \multicolumn{2}{|c|}{$\begin{array}{c}\text { TOTAL PRE } \\
\text { TESTE }\end{array}$} & \multicolumn{2}{|c|}{$\begin{array}{c}\text { TOTAL POS } \\
\text { TEST }\end{array}$} & \multicolumn{4}{|c|}{ PRE TEST } & \multicolumn{4}{|c|}{ POS TEST } \\
\hline & & & & & \multicolumn{2}{|c|}{ FAP } & \multicolumn{2}{|c|}{ HD } & \multicolumn{2}{|c|}{ FAP } & \multicolumn{2}{|c|}{ HD } \\
\hline & 53 & $100 \%$ & 53 & $100 \%$ & 40 & $75.5 \%$ & 13 & $24.5 \%$ & 40 & $75.5 \%$ & 13 & $24.5 \%$ \\
\hline Gender & $\begin{array}{l}\text { F-32 } \\
\text { M-21 }\end{array}$ & $\begin{array}{c}\text { F-60.4\% } \\
\text { M-39.6\% }\end{array}$ & $\begin{array}{l}\text { F-32 } \\
\text { M-21 }\end{array}$ & $\begin{array}{l}\text { F-60.4\% } \\
\text { M-39.6\% }\end{array}$ & $\begin{array}{l}\text { F-25 } \\
\text { M-15 }\end{array}$ & $\begin{array}{l}\text { F- } 47.2 \% \\
\text { M-28.3\% }\end{array}$ & $\begin{array}{l}\text { F-7 } \\
\text { M-6 }\end{array}$ & $\begin{array}{l}\text { F- } 13.2 \% \\
\text { M-11.3\% }\end{array}$ & $\begin{array}{l}\text { F-25 } \\
\text { M-15 }\end{array}$ & $\begin{array}{c}\text { F- } 47.2 \% \\
\text { M-28.3\% }\end{array}$ & $\begin{array}{l}\text { F-7 } \\
\text { M-6 }\end{array}$ & $\begin{array}{l}\text { F-13.2\% } \\
\text { M-11.3\% }\end{array}$ \\
\hline Age & 35.19 & 10.1 & 35.19 & 10.1 & 31.85 & 1.22 & 45.46 & 2.75 & 31.85 & 1.22 & 45.46 & 2.75 \\
\hline $\begin{array}{c}\text { Marital } \\
\text { Status }\end{array}$ & $\begin{array}{l}\text { S-24 } \\
\text { M-29 }\end{array}$ & $\begin{array}{c}\text { S- } 46.2 \% \\
\text { M- } 53.8 \%\end{array}$ & $\begin{array}{c}\text { S-24 } \\
\text { M-29 }\end{array}$ & $\begin{array}{c}\text { S- } 46.2 \% \\
\text { M- } 53.8 \%\end{array}$ & $\begin{array}{c}\text { S-22 } \\
\mathrm{M}-17\end{array}$ & $\begin{array}{c}\text { S- } 41.5 \% \\
\text { M-32.1\% }\end{array}$ & $\begin{array}{c}\text { S-2 } \\
\mathrm{M}-11\end{array}$ & $\begin{array}{c}\text { S-3.8\% } \\
\text { M- } 20.8 \%\end{array}$ & $\begin{array}{l}\mathrm{S}-22 \\
\mathrm{M}-17\end{array}$ & $\begin{array}{l}\text { S- } 41.5 \% \\
\text { M-32.1\% }\end{array}$ & $\begin{array}{l}\text { S-2 } \\
\text { M-11 }\end{array}$ & $\begin{array}{c}\text { S-3.8\% } \\
\text { M-20.8\% }\end{array}$ \\
\hline Test Result & & & & & & & & & $\begin{array}{c}\text { NC-10 } \\
\text { C-29 } \\
\text { DK-1 }\end{array}$ & $\begin{array}{c}\text { NC- } 18.9 \% \\
\text { C-54.7\% } \\
\text { DK- } 1.9 \%\end{array}$ & $\begin{array}{c}\mathrm{NC}-2 \\
\mathrm{C}-9 \\
\mathrm{DK}-2\end{array}$ & $\begin{array}{c}\mathrm{NC}-3.8 \% \\
\mathrm{C}-17.0 \% \\
\mathrm{DK}-3.8 \%\end{array}$ \\
\hline & Mean & $\mathrm{SD}$ & Mean & $\mathrm{SD}$ & Mean & SD & Mean & SD & Mean & SD & Mean & SD \\
\hline Somatization & 4.226 & 4.734 & 4.226 & 4.734 & 3.450 & 3.249 & 6.615 & 7.388 & 2.436 & 2.891 & 4.308 & 4.608 \\
\hline $\begin{array}{l}\text { Obs. } \\
\text { compulsive }\end{array}$ & 5.906 & 4.143 & 5.906 & 4.143 & 5.575 & 3.281 & 6.923 & 6.157 & 3.564 & 2.854 & 5.000 & 5.132 \\
\hline $\begin{array}{c}\text { Interp. } \\
\text { sensitivity }\end{array}$ & 3.094 & 2.870 & 3.094 & 2.870 & 2.875 & 2.729 & 3.769 & 3.295 & 2.184 & 2.502 & 2.231 & 2.242 \\
\hline Depression & 4.094 & 4.221 & 4.094 & 4.221 & 3.825 & 3.908 & 4.923 & 5.155 & 2.579 & 3.584 & 4.462 & 4.926 \\
\hline Anxiety & 4.415 & 3.734 & 4.415 & 3.734 & 4.050 & 3.146 & 5.539 & 5.142 & 2.711 & 2.818 & 4.385 & 3.618 \\
\hline Hostility & 3.877 & 3.238 & 3.877 & 3.238 & 3.437 & 3.036 & 5.231 & 3.586 & 2.711 & 2.660 & 4.539 & 3.733 \\
\hline $\begin{array}{l}\text { Phobic } \\
\text { anxiety }\end{array}$ & 2.038 & 2.572 & 2.038 & 2.572 & 2.500 & 2.512 & 2.154 & 2.853 & 1.079 & 1.667 & 1.692 & 3.449 \\
\hline $\begin{array}{l}\text { Paranoid } \\
\text { ideation }\end{array}$ & 4.472 & 3.195 & 4.472 & 3.195 & 4.725 & 3.202 & 3.692 & 2.750 & 3.263 & 3.064 & 2.750 & 1.815 \\
\hline Psychosis & 2.717 & 3.066 & 2.717 & 3.066 & 2.525 & 2.631 & 3.308 & 4.211 & 1.526 & 1.969 & 2.250 & 2.340 \\
\hline GSI & 0.703 & 0.526 & 0.703 & 0.526 & 0.652 & 0.431 & 0.861 & 0.749 & 0.446 & 0.394 & 0.564 & 0.534 \\
\hline PST & 23.132 & 12.862 & 23.132 & 12.862 & 22.150 & 12.027 & 26.154 & 15.285 & 15.850 & 12.817 & 21.690 & 13.634 \\
\hline PSD & 1.506 & 0.382 & 1.506 & 0.382 & 1.491 & 0.337 & 1.553 & 0.510 & 1.440 & 0.408 & 1.420 & 0.395 \\
\hline
\end{tabular}

The regression analyses enable exploring and infer the relationship of a dependent variable (response variable) with specific independent variables (explanatory variables). In linear regression is considered that the ratio of the response variables is a linear function of certain parameters.

Thus, when we present the values resulting from the stepwise method, for a sample of 53 subjects, taking as dependent variable the BSI somatization subscale, at first moment of data collection (pre-test) and as independent variables, the gender, marital status and type of disease (FAP and HD) variables, the final equation comprises only the variable type of disease $\left(\mathrm{R}^{2}=0.075 ; \mathrm{F}=5151\right.$; $\mathrm{df}=1 ; \mathrm{p}=0.028$ ) explaining $7.5 \%$ of the variance of this subscale.

When we present the values resulting from the stepwise method, for a sample of 53 subjects, taking as de- pendent variable the BSI depression subscale, at the last moment of data collection (pos-test) and as independent variables, the gender, marital status and type of diseases, the final equation comprises only the variable type of disease $\left(\mathrm{R}^{2}=0.062 ; \mathrm{F}=4173 ; \mathrm{df}=1 ; \mathrm{p}=0.047\right)$, explaining $6.2 \%$ of the variance of this subscale.

We proceeded making the linear regression analysis to the BSI anxiety subscale at post-test and the final equation comprises only the variable type of disease $\left(\mathrm{R}^{2}=\right.$ $0.065 ; \mathrm{F}=4320 ; \mathrm{df}=1 ; \mathrm{p}=0.043)$, explaining $6.5 \%$ of the variance of this subscale.

We also proceeded to a linear regression analysis to the BSI hostility subscale at post-test and the final equation comprises only the variable type of disease $\left(\mathrm{R}^{2}=\right.$ $0.061 ; \mathrm{F}=4125 ; \mathrm{df}=1 ; \mathrm{p}=0.048)$, explaining $6.1 \%$ of the variance of this subscale.

We proceeded making the linear regression analysis to 
Table 7. Average scores for the BSI subscales and indexes at post test (carriers and non carriers).

\begin{tabular}{|c|c|c|c|c|c|c|c|c|c|c|c|c|}
\hline \multirow[b]{3}{*}{$\mathbf{N}$} & \multicolumn{4}{|c|}{ POS TEST } & \multicolumn{4}{|c|}{ POS TEST-CARRIERS } & \multicolumn{4}{|c|}{ POS TES-NON CARRIERS } \\
\hline & \multicolumn{2}{|c|}{ CARRIERS } & \multicolumn{2}{|c|}{ NON CARRIERS } & \multicolumn{2}{|c|}{ FAP } & \multicolumn{2}{|c|}{ HD } & \multicolumn{2}{|c|}{ FAP } & \multicolumn{2}{|c|}{ HD } \\
\hline & 38 & $76 \%$ & 12 & $24 \%$ & 29 & $58 \%$ & 9 & & 10 & $83.3 \%$ & 2 & $16.6 \%$ \\
\hline Gender & $\begin{array}{l}\text { F-23 } \\
\text { M-15 }\end{array}$ & $\begin{array}{l}\text { F-60.5\% } \\
\text { M-38.5\% }\end{array}$ & $\begin{array}{l}\text { F-7 } \\
\text { M-5 }\end{array}$ & $\begin{array}{l}\text { F-63.6\% } \\
\text { M-36.4\% }\end{array}$ & $\begin{array}{l}\text { F-17 } \\
\text { M-12 }\end{array}$ & $\begin{array}{l}\text { F-58.6\% } \\
\text { M- } 41.4 \%\end{array}$ & $\begin{array}{l}\text { F-6 } \\
\text { M-3 }\end{array}$ & $\begin{array}{l}\text { F-66.7\% } \\
\text { M-33.3\% }\end{array}$ & $\begin{array}{l}\text { F-7 } \\
\text { M-3 }\end{array}$ & $\begin{array}{l}\mathrm{F}-70 \% \\
\mathrm{M}-30 \%\end{array}$ & $\begin{array}{l}\text { F-1 } \\
\text { M-1 }\end{array}$ & $\begin{array}{l}\text { F-50\% } \\
\text { M-50\% }\end{array}$ \\
\hline Age & 34.55 & 10.35 & 36.48 & 10.69 & 31.19 & 7.78 & 45.67 & 10.09 & 33.00 & 7.35 & 54.50 & 0.71 \\
\hline $\begin{array}{c}\text { Marital } \\
\text { Status }\end{array}$ & $\begin{array}{l}\text { S-19 } \\
\text { M-19 }\end{array}$ & $\begin{array}{l}\text { S- } 50 \% \\
\text { M- } 50 \%\end{array}$ & $\begin{array}{l}\text { S-5 } \\
\text { M-7 }\end{array}$ & $\begin{array}{c}\text { S- } 41.7 \% \\
\text { M-58.3\% }\end{array}$ & $\begin{array}{l}\text { S-17 } \\
\text { M-12 }\end{array}$ & $\begin{array}{c}\text { S-60.7\% } \\
\text { M-39.3\% }\end{array}$ & $\begin{array}{l}\text { S-2 } \\
\text { M-7 }\end{array}$ & $\begin{array}{c}\mathrm{S}-22.2 \% \\
\mathrm{M}-77.8 \%\end{array}$ & $\begin{array}{l}\text { S-5 } \\
M-5\end{array}$ & $\begin{array}{l}\text { S- } 50 \% \\
\text { M- } 50 \%\end{array}$ & $\begin{array}{l}\text { S-0 } \\
\text { M-2 }\end{array}$ & $\begin{array}{c}\text { S- }-0 \% \\
\mathrm{M}-100 \%\end{array}$ \\
\hline \multirow[t]{2}{*}{ Type disease } & $\begin{array}{c}\text { FAP-29 } \\
\text { HD-9 }\end{array}$ & $\begin{array}{c}\text { FAP-76.3\% } \\
\text { HD-23.7\% }\end{array}$ & & & & & & & & & & \\
\hline & Mean & SD & Mean & SD & Mean & SD & Mean & SD & Mean & SD & Mean & SD \\
\hline Somatization & 3.00 & 3.65 & 2.50 & 2.61 & 2.500 & 2.963 & 4.556 & 5.175 & 2.500 & 2.877 & 2.500 & 0.707 \\
\hline $\begin{array}{c}\text { Obs. } \\
\text { compulsive }\end{array}$ & 4.14 & 3.95 & 3.33 & 2.610 & 3.464 & 3.037 & 6.222 & 5.696 & 3.800 & 2.573 & 1.000 & 1.414 \\
\hline $\begin{array}{c}\text { Interp. } \\
\text { sensitivity }\end{array}$ & 2.42 & 2.62 & 1.83 & 1.95 & 2.333 & 2.689 & 2.667 & 2.550 & 2.000 & 2.055 & 1.000 & 1.414 \\
\hline Depression & 3.31 & 4.52 & 2.08 & 2.39 & 2.741 & 3.996 & 5.000 & 5.745 & 2.200 & 2.530 & 1.500 & 2.121 \\
\hline Anxiety & 3.22 & 3.54 & 2.75 & 1.60 & 2.667 & 3.199 & 4.889 & 4.167 & 2.800 & 1.751 & 2.500 & 0.707 \\
\hline Hostility & 3.06 & 3.18 & 3.42 & 3.09 & 2.333 & 2.564 & 5.222 & 4.177 & 3.600 & 3.169 & 2.500 & 2.536 \\
\hline $\begin{array}{l}\text { Phobic } \\
\text { anxiety }\end{array}$ & 1.33 & 2.22 & 1.25 & 1.76 & 0.963 & 1.63 & 2.444 & 3.972 & 1.500 & 1.841 & 0.000 & 0.000 \\
\hline $\begin{array}{l}\text { Paranoid } \\
\text { ideation }\end{array}$ & 3.06 & 2.75 & 3.67 & 3.20 & 3.185 & 3.039 & 2.625 & 1.506 & 3.800 & 3.225 & 3.000 & 4.243 \\
\hline Psychosis & 1.63 & 2.22 & 1.83 & 1.90 & 1.296 & 1.996 & 2.750 & 2.712 & 2.100 & 1.969 & 0.500 & 0.707 \\
\hline GSI & 0.48 & 0.47 & 0.46 & 0.34 & 0.434 & 0.416 & 0.639 & 0.662 & 0.494 & 0.364 & 0.311 & 0.173 \\
\hline PST & 16.63 & 13.74 & 18.42 & 12.85 & 14.59 & 12.757 & 23.220 & 15.458 & 19.800 & 13.497 & 11.500 & 7.778 \\
\hline PSD & 1.51 & 0.45 & 1.29 & 0.23 & 1.520 & 0.447 & 1.470 & 0.469 & 1.250 & 0.219 & 1.51 & 0.222 \\
\hline
\end{tabular}

the BSI phobic anxiety subscale at post-test and the final equation comprises only the variable gender $\left(R^{2}=0.068\right.$; $\mathrm{F}=4477 ; \mathrm{df}=1 ; \mathrm{p}=0.040)$, explaining $6.8 \%$ of the variance of this subscale.

In summary, the independent variable type of disease contributes to the explanation of the dependent variables somatization (pre-test) and depression, anxiety and hostility (post-test). Furthermore, the independent variable gender partially explains the dependent variable phobic anxiety at post-test, with averages among men (0.700) and female (1581) differing, although this difference was not significant.

\section{DISCUSSION}

The pre and post-test BSI values were higher than the general population values, presented by Canavarro [17]. However, they were not as high as those of the population considered by the author as suffering from emo- tional disturbance at the time of the standardization of the scale for the Portuguese population [17]. Indeed, there were no values mirroring the existence of emotional distress, even for those subjects who received the result of carriers for the two studied diseases (pre-test carriers $\mathrm{PSD}=1.47, \mathrm{SD}=0.40 ;$ post-test $\mathrm{PSD}=1.52$, $\mathrm{SD}=0.44)$.

It was found that the average values for all subscales of the BSI declined significantly after the year in which the outcome of PST was made. There was also a decrease in the average values obtained for the GSI and PST scores. With respect to the subjects at risk for FAP, the values of the BSI subscales and indexes are also lower at post-test moment than at the pre-test; the same applies to subjects at risk for HD. In no time, the PSD value equaled or exceeded the cut point.

Beyond the different socioeconomic circumstances which were not controlled in this study, one could say 
Table 8. Comparison between the average scores of the different BSI subscales in pre-test (BSIa) and at post-test (BSId).

\begin{tabular}{|c|c|c|c|c|c|c|}
\hline \multicolumn{2}{|c|}{ BSI Subscales } & \multirow{2}{*}{$\begin{array}{c}\text { Mean } \\
4.269\end{array}$} & \multirow{2}{*}{$\begin{array}{l}N \\
53\end{array}$} & \multirow{3}{*}{$\begin{array}{c}\boldsymbol{t} \\
3.095\end{array}$} & \multirow{3}{*}{$\begin{array}{c}\text { d. } f \text {. } \\
53\end{array}$} & \multirow{3}{*}{$\begin{array}{c}\text { Sig. (2-tailed) } \\
0.003\end{array}$} \\
\hline & BSIa & & & & & \\
\hline Somatization & BSId & 2.904 & 53 & & & \\
\hline \multirow[b]{2}{*}{ Obsessive-compulsive } & BSIa & 5.961 & 53 & \multirow[b]{2}{*}{4.137} & \multirow[b]{2}{*}{53} & \multirow[b]{2}{*}{0.000} \\
\hline & BSId & 3.923 & 53 & & & \\
\hline \multirow{2}{*}{ Interpersonal sensitivity } & BSIa & 3.216 & 53 & \multirow{2}{*}{2.929} & \multirow{2}{*}{53} & \multirow{2}{*}{0.005} \\
\hline & BSId & 2.196 & 53 & & & \\
\hline \multirow{2}{*}{ Depression } & BSIa & 4.196 & 53 & \multirow{2}{*}{2.321} & \multirow{2}{*}{53} & \multirow{2}{*}{0.024} \\
\hline & BSId & 3.059 & 53 & & & \\
\hline \multirow[b]{2}{*}{ Anxiety } & BSIa & 4.549 & 53 & \multirow[b]{2}{*}{2.778} & \multirow[b]{2}{*}{53} & \multirow[b]{2}{*}{0.008} \\
\hline & BSId & 3.137 & 53 & & & \\
\hline \multirow[b]{2}{*}{ Hostility } & BSIa & 4.029 & 53 & \multirow[b]{2}{*}{2.220} & \multirow[b]{2}{*}{53} & \multirow[b]{2}{*}{0.031} \\
\hline & BSId & 3.177 & 53 & & & \\
\hline \multirow{2}{*}{ Phobic anxiety } & BSIa & 2.118 & 53 & \multirow{2}{*}{2.463} & \multirow{2}{*}{53} & \multirow{2}{*}{0.017} \\
\hline & BSId & 1.235 & 53 & & & \\
\hline \multirow{2}{*}{ Paranoid ideation } & BSIa & 4.380 & 53 & \multirow{2}{*}{3.012} & \multirow{2}{*}{53} & \multirow{2}{*}{0.004} \\
\hline & BSId & 3.140 & 53 & & & \\
\hline \multirow{2}{*}{ Psychosis } & BSIa & 2.600 & 53 & \multirow{2}{*}{2.570} & & \\
\hline & BSId & 1.700 & 53 & & & 0.015 \\
\hline
\end{tabular}

that the results mean that despite the fact that the sample cannot be regarded as suffering from emotional problems, it also does not share the same lack of emotional distress as observed in the general population. These results may contradict published studies which have described higher levels of psychological well-being in subjects at risk compared to the general population $[14,19,20]$ and in which this tendency has been justified with a self-selection process developed by the most psychologically prepared subjects prior to the PST, explanation widely accepted by several studies [3,14,19-21].

On the one hand, these results highlight the need for psychological support in the implementation of predictive testing, since the psychological suffering of individuals at risk may precede by many years the clinical onset of the disease [22]. On the other hand, a significant decrease in the values of some BSI subscales and indexes, in the post-test, is another important result of this study. This could possibly mean that the subjects have higher values of psychopathology at the pre-test moment, which may be due to the fact that the pre-test could trigger more significant psychosocial symptoms in the day-to-day lives of the subjects. Again, this seems to reaffirm the need for psychological counseling and, in some cases, psychiatric, of these subjects during the process of ge- netic counseling [23]. Other assumptions are related to the character and even beneficial nature of therapeutic protocols that have been developed to support information and counseling, and are included in the PST general protocols [3,14,20,21], as well as the favorable impact of reducing uncertainty and gain the sense of control over the disease resulting from an established pre-symptomatic diagnosis $[14,15,24]$.

If we compared samples for FAP and HD, we found that, at pre-test, subjects at risk for HD present higher values for all BSI subscales and indexes, except for phobic anxiety and paranoid ideation subscales. It is surprising that the subjects at risk for FAP seems to come for predictive testing more frightened than subjects at risk for HD; usually, the subjects at risk for FAP have more hope due to the possibility of liver transplantation and new drugs under study.

At pre-test, one socio-demographic variable for which the BSI score averages showed statistically significant differences was the marital status, which seems to point to the hypothesis that people who feel lonelier may be more likely to somatize and show a higher degree of psychopathology. This may be related to the personal perception of a possible lack of emotional support and more effective future care, due to the possible inexist- 
ence of a caregiver. This perception may lead the subject to a state of higher internal anguish that cannot be externalized differently (like matured mentally), and does so somatically (through physical symptoms). The presence of a somatic pathway for the expression of affection has been described in this population $[11,15]$.

Another variable that showed statistically significant results was type of disease. The somatization subscale revealed statistically significant different values in relation to type of disease: subjects at risk for FAP had lower average scores of somatization than subjects at risk for HD. Indeed, the type of disease contributes to the explanation of the dependent variable somatization. This may be related to HD characteristics, namely, behavioral changes prior to neurological disorders, what leads a person at risk for HD to have more somatic complaints.

The subjects who transitioned from pre-test moment to post-test are mainly carriers. Almost all non-carriers do not understand the need to remain in predictive testing protocol after knowing their genetic status of non-carrier; so, after some time, they fail to attend. Even if they understand the need to keep the protocol until the end, labor and economic constraints eventually prevent them from continuing.

When comparing carriers and non carriers samples, at post-test, we found that carriers present higher values for all BSI subscales and indexes, except for hostility, paranoid ideation and psychosis subscales and PST index. We understand better that carriers have higher values in most of the BSI subscales and indexes than non-carriers have higher values on the hostility, psychosis and paranoid ideation subscales as well in PST index. Eventually, paranoid ideation and psychosis may be explained by the suspicion that some non carriers keep in relation to their genetic status: the need to stay at the predictive test protocol can be interpreted as having the possibility of becoming carriers. Hostility seems to be better explained by the fact that some patients remain in the protocol thwarted.

One previous study only with FAP carriers [12] also found that most of them did not have psychological disturbance or sense of hopelessness after a year of knowing their genetic status. One of the explanations given by the authors was that the personality structure of these subjects that can be very similar to that of psychosomatic personalities. This present a very poor capacity for symbolic thinking or subjectivity, therefore, they present difficulty to draw up mentally their negative emotions (internal anguish). Perhaps this could explain the high values recorded in the somatization subscale in subjects without a partner, translating their difficulty to accept this reality. This explanation that emphasizes this kind of personality structure found in the population of carriers of FAP, may also explain why, once again, and also in the present study, emotional disturbance was not found resulting from the knowledge of genetic status (carrier or non carrier). This may then be justified by the existence of a type of personality structure near psychosomatic personalities in which the individual has very rigid defense mechanisms, repressing anything that might be disturbing, trying to avoid thinking about a reality that causes so much anguish.

When comparing samples of FAP and HD carriers, at post-test, we found that HD carriers present higher values for all BSI subscales and indexes, except paranoid ideation subscale and PSD. Again, we become surprised with FAP carriers (as well as the non carriers, like we said above) having higher levels of paranoid ideation.

If we compare samples of FAP and HD non carriers, at post-test, we found that FAP non carriers present higher values for all BSI subscales and indexes; this can be explained by the low number of HD non carriers that remained in the protocol.

Specifically, the finding of higher post-test hostility in subjects at risk for HD (regardless of the molecular results obtained) may be related to the clinical characterization of this disease, unique for the neurodegenerative diseases here studied, that presents mental deterioration prior to the motor and autonomic symptoms. Thus, the nature and the subjective perception of the degree of severity and prognosis of the disease felt by affected or at risk individuals should be weighed $[3,25]$. It is interesting to note that the type of disease is the variable that best predicts some of the subscales of the BSI (somatization in pre-test and depression, anxiety and hostility in post-test).

Finally, the variable gender partially explains the dependent variable phobic anxiety at post-test, with averages among men (0.700) and female (1.581) differing, although this difference was not significant. The higher levels of psychopathology found in female subjects are a finding consistent with different previous publications $[3,19]$. It is worth noting that a higher trend in men's denial of feelings has been recognized. The predictive nature of the socio-demographic variables of the population that underwent the PST, as well as their levels of psychological functioning have been widely discussed $[3,7,14,21,24,25]$. For its clinical relevance in the establishment of more timely intervention in those individuals identified as vulnerable, this is indeed one of the most relevant results of the study. Nevertheless, despite the establishment of predictive variables under study, the need for a careful and personalized support for each individual who came to consummate the PST continues to be an ethical principle that needs to be established $[2,3]$.

Therefore, we can say that the group of subjects here studied is a distinguished population and, as in other studies for Portuguese samples, such populations have 
higher values on the BSI subscales than the general population. This result is consistent with previous studies, for example, patients with fibromyalgia [26], drug addicts [27] or mothers with children with cerebral paralysis [28] on the Portuguese population.

\section{CONCLUSION AND CLINICAL IMPLICATIONS}

There is a decrease in average values between the preand post-test moments regarding the studied psychopathological scores, stating that subjects have higher levels of psychopathology prior to pre-symptomatic testing than one year after notification of genetic test results. That's why this research reveals the need for the existence of a rigorous protocol of consultation and evaluation of genetic counseling and psychosocial support, from the base line to a considerable post-test period with emphasis on symbolic representation of the disease and self coping mechanisms to face all the disease information and the condition of being a carrier or a non carrier with a past history or relatives with the disease. Another need perhaps is the future implementation of therapeutic groups with goals of psychosocial support for this population.

The inherent characteristics of each disease, as well as the knowledge of the genetic status - be a carrier or non carrier-do not seem to significantly influence the existence of emotional distress, as would initially be expected. Only the gender and marital status variables were important in the oscillation of the values of psychopathological scores, stating that it was women who had the highest values, as well as the single or widow individuals.

Although there were no observed score inductors of a degree of psychopathological disturbance (higher than 1.7) we cannot, however, conclude that the pre-symptomatic testing for these diseases does not affect the individuals, since all the values found in our results are higher than the reference values for general population. This suggests that these subjects did not show complete absence of emotional disturbance. For this reason, there must be given increasing attention to the individual characteristics of each subject and adapt the psychological support to each individual's needs, since it is a population that has different ways of coping with psychological distress.

\section{REFERENCES}

[1] International Huntington Association and World Federation of Neurology Research Group on Huntington's Disease (1994) Guidelines for the molecular genetics predictive test in Huntington's disease. Journal of Medical Genetics, 31, 555-559.

http://dx.doi.org/10.1136/jmg.31.7.555
[2] Sequeiros, J. (1996) Genetic Counseling and the Predictive Testing for Machado-Joseph Disease. In: Sequeiros, J. (Ed.), The Predictive Testing for Machado-Joseph Disease, UnIGENe, IBMC, Porto, pp. 97-112.

[3] Paneque, H.M., Prieto, A.L., Reynaldo, R.R., Cruz, M.T., Santos, F.N., Almaguer, M.L., et al. (2007) Psychological aspects of presymptomatic diagnosis of spinocerebellar Ataxia type 2 in Cuba. Community Genetics, 10, 132-139. http://dx.doi.org/10.1159/000101754

[4] Lerman, C. (1997) Psychological aspects of genetic testing: introduction to the special issue. Health Psychology, 1, 3-7. http://dx.doi.org/10.1037/h0092702

[5] Decruyenaere, M., Evers-Kiebooms, G. and Van Den Berghe, H. (1997) Non-participation in predictive testing for Huntington's Disease: Individual decision-making, personality and avoidant behavior in the family. European Journal of Human Genetics, 5, 351-363

[6] Almqvist, E.W., Bloch, M. and Hayden, M. (1999) A worldwide assessment of the frequency of suicide, suicide attempts, or psychiatric hospitalization after predictive testing for Huntington Disease. American Journal of Human Genetics, 64, 1293-1304.

http://dx.doi.org/10.1086/302374

[7] Codori, A., Slavney, P.R. and Brandt, J. (1997) Predictors of psychological adjustment to genetic testing of Huntington's Disease. Health Psychology, 1, 36-50. http://dx.doi.org/10.1037/0278-6133.16.1.36

[8] Tibben, A., Timman, R., Bannink, E. and Duivenvoorden, H. (1997) Three years follow-up after presymptomatic testing for Huntington's Disease in tested individuals and partners. Health Psychology, 1, 20-35. http://dx.doi.org/10.1037/0278-6133.16.1.20

[9] Saraiva, M.J. and Costa, P. (1986) Familial Amyloidotic Polyneuropathy, Portuguese type: Phenotype and genotype. In: Sales-Luís, M.L., Ed., Symposium on Peripheral Neuropathies, Lisboa, pp. 207-212.

[10] Lopes, A. and Fleming, M. (1996) The Somatic Disease and the psychic Organization: A reflection: Considerations starting from the Familiar Amyloidotic Polyneuropathy. Portuguese Journal of Psychoanalysis, 15, 93-100.

[11] Lopes, A. and Fleming, M. (1998) Psychological Aspects of the Familial Amyloidotic Polyneuropathy: The intergenerational underground storyline. Brotéria Genétics, 19, 183-192.

[12] Lêdo, S. (2002) The First day of the rest of their lives. Some psychological aspects of FAP. MSc Dissertation, ISPA Lisbon.

[13] Leite, A. (2006) Psychosocial Determinants of Adherence for pre-symptomatic testing of the late onset neurological genetic diseases. Ph.D. Dissertation, Instituto de Ciências Biomédicas Abel Salazar, University of Porto.

[14] Rolim, L., Leite, A., Ledo, S., Paneque, M., Sequeiros, J. and Fleming, M. (2006) Psychological aspects of presymptomatic testing for Machado-Joseph disease and familial amyloid polyneuropathy type I. Clinical Genetics, 69, 297-305. http://dx.doi.org/10.1111/j.1399-0004.2006.00606.x

[15] Paneque, H.M., Lemos, C., Sousa, A., Velázquez, P.L., Fleming, M. and Sequeiros, J. (2009) Role of the disease 
in the psychological impact of pre-symptomatic testing for SCA2 and FAP ATTRV30M: Experience with the disease, kinship and gender of the transmitting parent. Journal of Genetic Counseling, 18, 483-493. http://dx.doi.org/10.1007/s10897-009-9240-1

[16] Derogatis, L.R. (1993) BSI: Brief Symptom Inventory. Nacional Computers Systems, Minneapolis.

[17] Canavarro, C. (1999) Psychopathological Sintomatic Inventory-BSI. In: Simões, M., Gonçalves, M. and Almeida, L., Eds. Psychological Test and Scales in Portugal (Vol. 2), APPORT/SHO, Braga, 305-331.

[18] Canavarro, C. (2007) Psychopathological Sintomatic Inventory (BSI) A critical revision of the portuguese studies. In: Simões, M., Machado, C., Gonçalves, M. and Almeida, L., Eds., Psychological Evaluation. The Validated Scales for the Portuguese Population (Vol. 3), Quarteto Editora, Lisboa.

[19] Bloch, M., Fahy, M., Fox, S. and Hayden, M. (1989) Presymptomatic testing for Huntington disease: II. Demographic characteristics, life-style patterns, attitudes, and psychosocial assessments of the first fifty-one test candidates. American Journal of Medical Genetics, 32, 217224. http://dx.doi.org/10.1002/ajmg.1320320215

[20] Codori, A.M., Hanson, R. and Brandt, J. (1994) Selfselection in predictive testing for Huntington's disease. American Journal of Medical Genetics, 54, 167-173. http://dx.doi.org/10.1002/ajmg.1320540303

[21] Tibben, A. (2007) Predictive testing for Huntington's disease. Brain Result Bulletin, 72, 165-171. http://dx.doi.org/10.1016/j.brainresbull.2006.10.023
[22] Sequeiros, J. (1998) Prenatal diagnosis of late-onset diseases. Progresos en Diagnóstico Prenatal, 10, 218-220.

[23] Weil, J. (2003) Psychosocial genetic counseling in the post-nondirective era: A point of view. Journal of Genetic Counseling, 12, 199-211. http://dx.doi.org/10.1023/A:1023234802124

[24] Almqvist, E.W., Brinkman, R.R., Wiggins, S. and Hayden, M.R. (2003) Canadian Collaborative Study of Predictive Testing. Psychological consequences and predictors of adverse events in the first 5 years after predictive testing for Huntington's disease. Clinical Genetics, 64, 300-309. http://dx.doi.org/10.1034/j.1399-0004.2003.00157.x

[25] DudokdeWit, A.C., Tibben, A., Duivenvoorden, H.J., Niermeijer, M.F. and Passchier, J. (1998) Predicting adaptation to presymptomatic DNA testing for late onset disorders: Who will experience distress? Rotterdam Leiden Genetics Workgroup. Journal of Medical Genetics, 35, 745-754. http://dx.doi.org/10.1136/jmg.35.9.745

[26] Quartilho, M. (1999) Fibromyalgia e Somatization. Ph.D. Dissertation, University of Coimbra.

[27] Almeida, D., Vieira, C., Rijo, D. and Felisberto, A. (2005) Addiction and psychiatric comorbidity: Axis I Symptomatology and personality disorders. Clinical Psychiatry, 26, 55-70.

[28] Monteiro, M., Matos, A. and Coelho, R. (2004) Psychological adaptation of mothers whose children have cerebral paralysis: A study result. Portuguese Journal of Psychosomatic, 6, 115-130. 